\title{
Mitochondrial energy metabolism is required for lifespan extension by the spastic paraplegia-associated protein spartin
}

\author{
Julia Ring ${ }^{1}$, Patrick Rockenfeller ${ }^{1,}{ }^{3}$, Claudia Abraham ${ }^{1}$, Jelena Tadic ${ }^{1}$, Michael Poglitsch ${ }^{1}$, Katherina \\ Schimmel $^{1,4}$, Julia Westermayer ${ }^{1}$, Simon Schauer ${ }^{1}$, Bettina Achleitner ${ }^{1}$, Christa Schimpel ${ }^{1,5}$, Barbara Moitzi ${ }^{1}$, \\ Gerald N. Rechberger ${ }^{1,6}$, Stephan J. Sigrist ${ }^{7,8}$, Didac Carmona-Gutierrez ${ }^{1}$, Guido Kroemer ${ }^{9,10,11,12,13,14,15}$, \\ Sabrina Büttner ${ }^{1,16}$, Tobias Eisenberg ${ }^{1,2}$, Frank Madeo ${ }^{1,2, *}$ \\ ${ }^{1}$ Institute of Molecular Biosciences, NAWI Graz, University of Graz, Graz, Austria. ${ }^{2}$ BioTechMed Graz, Graz, Austria. ${ }^{3}$ Kent Fungal \\ Group, School of Biosciences, University of Kent, Canterbury, UK. ${ }^{4}$ Institute of Molecular and Translational Therapeutic Strategies \\ (IMTTS), IFB-Tx, Hannover Medical School, Hannover, Germany. ${ }^{5}$ BioNanoNet Forschungsgesellschaft mbH, Graz, Austria. ${ }^{6}$ Omics \\ Center Graz, BioTechMed-Graz, Graz, Austria. ${ }^{7}$ Institute for Biology, Freie Universität Berlin, Berlin, Germany. ${ }^{8}$ NeuroCure, Charité, \\ Berlin, Germany. ${ }^{9}$ Equipe 11 Labellisée Ligue Contre le Cancer, Centre de Recherche des Cordeliers, Paris, France. ${ }^{10}$ Cell Biology and \\ Metabolomics Platforms, Gustave Roussy Comprehensive Cancer Center, Villejuif, France. ${ }^{11}$ INSERM, U1138, Paris, France. \\ 12 Université Paris Descartes, Sorbonne Paris Cité, Paris, France. ${ }^{13}$ Université Pierre et Marie Curie, Paris, France. ${ }^{14}$ Pôle de Biologie, \\ Hôpital Européen Georges Pompidou, Paris, France. ${ }^{15}$ Karolinska Institute, Department of Women's and Children's Health, Karolinska \\ University Hospital Stockholm, Sweden. ${ }^{16}$ Department of Molecular Biosciences, The Wenner-Gren Institute, Stockholm University, \\ Stockholm, Sweden. \\ * Corresponding Author:
}

Frank Madeo, Humboldtstrasse 50/EG8010 Graz, Austria; Tel. +43 (0)316 380 - 8878; Fax +43 (0)316 380 - 9898; E-mail:

frank.madeo@uni-graz.at

ABSTRACT Hereditary spastic paraplegias, a group of neurodegenerative disorders, can be caused by loss-of-function mutations in the protein spartin. However, the physiological role of spartin remains largely elusive. Here we show that heterologous expression of human or Drosophila spartin extends chronological lifespan of yeast, reducing age-associated ROS production, apoptosis, and necrosis. We demonstrate that spartin localizes to the proximity of mitochondria and physically interacts with proteins related to mitochondrial and respiratory metabolism. Interestingly, Nde1, the mitochondrial external NADH dehydrogenase, and Pda1, the core enzyme of the pyruvate dehydrogenase complex, are required for spartin-mediated cytoprotection. Furthermore, spartin interacts with the glycolysis enhancer phospo-fructokinase-2,6 (Pfk26) and is sufficient to complement for PFK26-deficiency at least in early aging. We conclude that mitochondria-related energy metabolism is crucial for spartin's vital function during aging and uncover a network of specific interactors required for this function. doi: $10.15698 /$ mic2017.12.603 Received originally:21.10.2017; In revised form: 20.11.2017, Accepted: 29.11.2017, Published 30.11.2017.

Keywords: SPG20, mitochondria, metabolism, respiration, pyruvate dehydrogenase, cell death, aging.
Abbreviations:
$d S p$ - Drosophila spartin, HSP - hereditary spastic paraplegia, MIT - microtubule-interacting and trafficking domain,
$P D H$ - pyruvate dehydrogenase, $P S D$ - plant-related senescence domain,
ROS - reactive oxygen species.

\section{INTRODUCTION}

Troyer Syndrome, a complicated form of hereditary spastic paraplegias (HSPs), is caused by mutations in the gene coding for spartin (SPG20), resulting in a dysfunctional protein. This loss-of-function disease is characterized by neurological and musculoskeletal symptoms [1]. Spartin is conserved throughout multicellular eukaryotes, although expressed in all tissues, it seems to be of particular importance in neu- rons. This may explain the HSP-associated symptoms in the absence of the protein [2-6]. The medical relevance of spartin goes beyond neurodegeneration, since the epigenetic silencing via hypermethylation of SPG2O is associated with colorectal and gastric cancer. In fact, SPG2O has been recently introduced as a new biomarker for these diseases $[7,8]$. 
Despite several proposed molecular functions of spartin, its precise role to regulate cellular processes remains poorly understood. Spartin carries at least four different protein-interacting and binding domains: the $\mathrm{N}$-terminal microtubule-interacting and trafficking (MIT) domain, the Cterminal plant-related senescence domain (PSD), the ubiquitin binding region (UBR), and a protein-protein interaction PPxY motif [9-11]. Diverse studies elucidating spartin's cellular localization and interaction partners indicate a rather complex subcellular distribution [10, 12-20]. It is found in endosomes, the nucleus, the trans Golgi network, synaptogamin-positive vesicles, the spindle poles and the midbodies during mitosis, mitochondria, the ER, microtubules, and lipid droplets. It is also known to interact with ER- and mitochondria-associated heat shock proteins and proteins of the endosomal sorting complex required for transport III (ESCRT-III). Altogether, this suggests a plethora of diverse roles within the cell. Indeed, spartin has been postulated to impact a number of pathways. Spartin has been shown to impact synaptic growth and neuronal survival by regulating microtubule stability and endocytosis and by that to influence BMP (Bone Morphogenetic Protein)-signaling via its MIT domain [21-24]. Furthermore, this MIT domain has been reported to interact with an ESCRT-III-associated protein Ist1, which recruits spartin to midbodies for subsequent successful abscission during cytokinesis [7, 18, 22]. Several studies report a role for spartin in lipid droplet turnover, where it acts as an adaptor protein that activates and recruits ubiquitin ligases via its PPxY domain, thus promoting the ubiquitination of other lipid droplet-associated proteins [10, 13, 25]. Additionally, it has been shown to be involved in the formation of aggresome-like structures by binding ubiquitin chains via the UBR domain [26]. Interestingly, spartin binds to mitochondria via its PSD domain, but its function there remains elusive [15].

Yeast lacks an obvious DNA sequence-based SPG20 homolog and therefore may offer a "clean room" to explore spartin's functions. Importantly, yeast represents a well-established and powerful model organism to study metazoan proteins associated with neurodegenerative diseases [27-33]. In addition, chronologically aging yeast cells display similar aging and cell death processes as aging post mitotic neuronal cells, and represent an intrinsic physiological model of eukaryotic cell death [34-36]. Notably, mitochondria and their functions in energy metabolism and cell death are highly conserved from yeast to human [37-39]. In this study, we made use of this and analyzed heterologous expression of Drosophila and human spartin in aging yeast, demonstrating a cytoprotective function of the protein that is connected to glycolytic and respiratory control.

\section{RESULTS}

\section{Spartin increases survival of aging yeast cells}

Spartin is present in organisms ranging from nematodes and flies to humans, and alignment of Drosophila and human spartin shows that the C-terminal PSD, the $\mathrm{N}$-terminal
MIT as well as the centrally located UBR domains are highly conserved (Fig. S2) [21]. HSPs manifest in early childhood and progress during aging. Therefore we analyzed the impact of spartin on the aging process by heterologously expressing Drosophila spartin in yeast cells that were subjected to chronological aging. Expression of spartin in wild type cells (Fig. S1A) decreased age-associated clonogenic cell death (Fig. 1A) and reduced production of reactive oxygen species (ROS) (Fig. 1B), as quantified via superoxide-driven conversion of non-fluorescent dihydroethidium (DHE) into fluorescent ethidium [40, 41]. We next analyzed the mode of cell death affected by spartin expression and performed AnnexinV/PI co-staining, which allows to distinguish between early apoptosis (Annexin $\mathrm{V}+/ \mathrm{PI}-$ ), late apoptosis/secondary necrosis (Annexin $\mathrm{V}+/ \mathrm{PI}+$ ), and primary necrosis (Annexin $\mathrm{V}-/ \mathrm{PI}+$ ) $[29,42]$. Spartin reduced markers of both apoptotic and necrotic cell death (Fig. 1C). Of note, while spartin exerted cytoprotection in every aging experiment performed, the kinetics of this cytoprotective effect varied slightly between the independent experiments.

Spartin localizes in close proximity to mitochondria and interacts with proteins involved in energy metabolism

In many scenarios, cell death is strictly connected to mitochondria. Using a spartin-GFP fusion protein, we detected spartin in stationary cells either at the plasma membrane or in punctae in close proximity to mitochondria as visualized by co-expression with DsRed fused to a mitochondrial localization sequence (Fig. 1D). Co-immunoprecipitation followed by mass spectrometry corroborated spartin's mitochondrial connection. Among the proteins that copurified with spartin were several ones involved in vesicle transport (e.g. Yip3, an COPII vesicle interacting protein involved in ER to Golgi transport, the sorting nexin family member Atg20, which is required for cytosplama-tovacuole targeting pathway and endosomal sorting as well as Sec4, a Rab family GTPase essential for vesicle-mediated exocytic secretion and autophagy) according to spartin's proposed role in endosomal trafficking, but also a set of mitochondrial proteins (Table 1; Fig. S3A, B). Among those were regulators of mitochondria-associated proteostasis like Ssc1, an essential mitochondrial Hsp70 chaperone and component of the inner mitochondrial membrane translocase complex, and the cytosolic Hsp82/Hsc82, which are Hsp90 chaperones and among other functions important for outer mitochondrial membrane transport and the acetolactate synthase Ilv2. Further proteins involved in mitochondrial metabolism include the 6-phosphofructo-2kinase Pfk26 and the mitochondrial external NADH dehydrogenase Nde1.

Given the central role of mitochondria in cellular energy metabolism and the fact that glycolytic metabolic networks are often dysregulated in neurodegenerative diseases, we decided to focus on two main energy metabolismassociated interaction partners, Pfk26 and Nde1. Pfk26 stimulates glycolysis via activation of Pfk1 that converts fructose-6-phosphate to fructose-1,6-bisphosphate, thus 
A

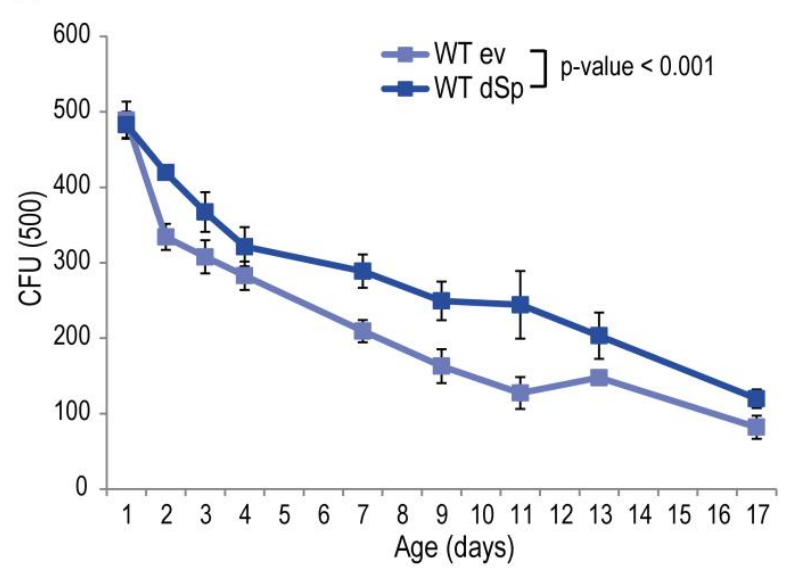

B

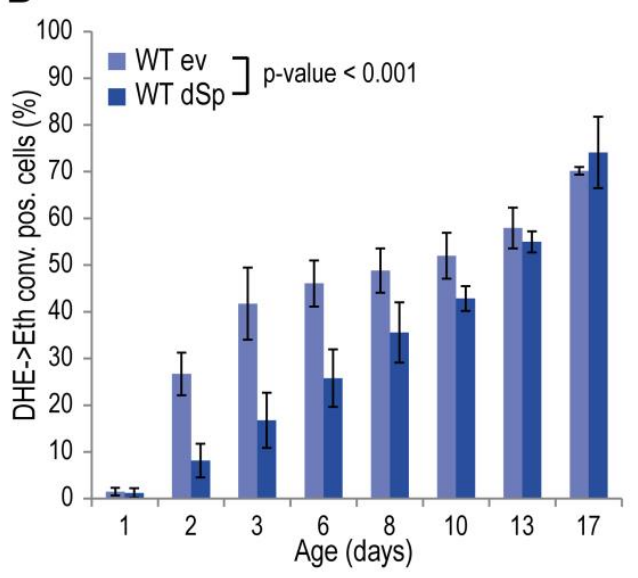

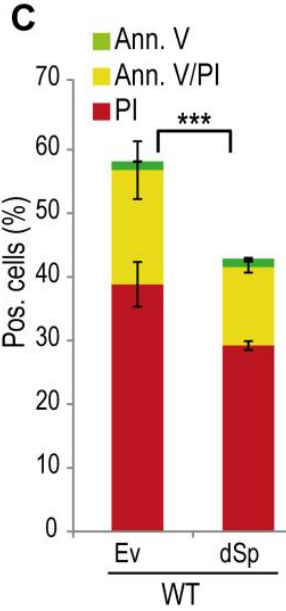
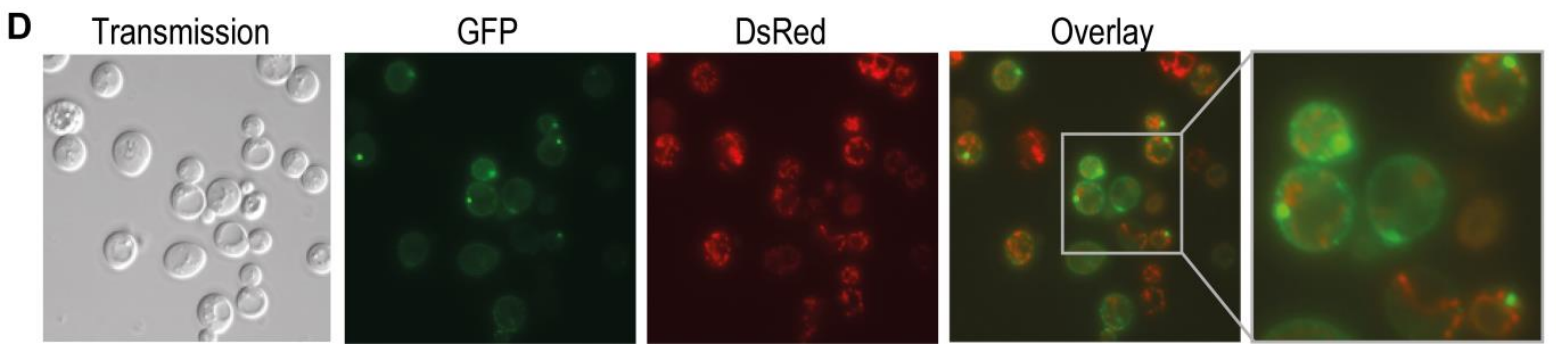

FIGURE 1: Spartin exerts a pro survival function in yeast. (A) Survival during chronological aging of WT cells expressing Drosophila spartin (dSp) or cells harboring the corresponding empty vector control (ev). Yeast cells were evaluated for clonogenicity at indicated time points after induction of expression by shift to $2 \%$ galactose containing media. Data represent mean values of at least four independent experiments performed at the same time. CFU, colony-forming unit. Error bars represent standard error of mean (SEM). (B) Quantification of oxidative stress levels (by conversion of dihydroethidium (DHE) to ethidium (Eth)). (C) phosphatidylserine externalization (apoptotic cell death) and loss of membrane integrity (necrotic cell death) using annexin V/propidium iodide (Ann.V/PI) costaining and flow cytometryassisted quantification. (D) Fluorescence microscopy of WT cells expressing dSp ${ }^{\mathrm{EGFP}}$ (green) and mitochondria visualized by co-expression with DsRed fused to a mitochondrial localization sequence on day 1 of chronological aging.

driving glycolysis to produce energy and the glycolytic end product pyruvate. We analyzed spartin expression upon deletion of PFK26, which per se caused an increase in ROS and cell death early during aging (Fig. 2A, B). This could be prevented by spartin expression, however, only at the beginning, but not as aging progressed (Fig. 2A, B). Deletion of PFK27, which codes for a Pfk26 paralogue specifically active during fermentation, had no effect on spartinmediated cytoprotection (Fig. S4A, B). Therefore, Pfk26 seems to be specifically involved in the spartin effects. Expression levels of dSp were similar in all strains (Fig. S1B, S4B).

Another identified spartin interactor that is involved in metabolism was Nde1, which is the yeast complex I-like enzyme that provides electrons from cytosolic NADH to the mitochondrial respiratory chain. Interestingly, spartin expressed in cells lacking Nde1 lost its beneficial effects and even caused toxicity at later stages of aging (Fig. 2C, D). Quantification of total cellular ATP levels suggested increased ATP production upon spartin expression, pointing to enhanced respiratory capacity (Fig. 2E). To test whether mitochondrial function and, in particular, active respiration are a general requirement for the cytoprotective effects of spartin, we analyzed its effect in $r h o^{\circ}$ cells, which lack mi- tochondrial DNA and are thus respiratory-deficient. Indeed, spartin-mediated cytoprotection was lost in the rho ${ }^{\circ}$ background (Fig. 2F). Of note, expression levels of dSp were similar in all strains (Fig. S1B).

Altogether, spartin cytoprotection depends on the mitochondrial-glycolytic axis that determines cellular energy metabolism.

\section{The pyruvate dehydrogenase complex contributes to spartin-mediated protection}

The glycolytic products NADH and pyruvate are imported from the cytosol into mitochondria to feed into oxidative phosphorylation. While mitochondrial NADH is converted by Nde1, pyruvate is transported into mitochondria by the pyruvate dehydrogenase (PDH) complex. Given the dependency of spartin on Nde1 (Fig. 2C, D), we next tested spartin expression in cells lacking Pda1, a core enzyme of the PDH complex essential for its function. Deletion of PDA1 led to increased cell death and ROS production during chronological aging and to a complete abrogation of the cytoprotective capacity of spartin (Fig. 3A, B). The activity of the PDH complex is regulated by the phosphatase Ptc6 and the kinase Pkp1, which act on Pda1 and promote 
or inhibit PDH activity, respectively [14]. We thus testedspartin expression upon deletion of these regulators. In PTC6-deficient cells, i.e. with decreased PDH complex activity, spartin expression was able to exert its beneficial effects (Fig. 3C, D). Notably, human spartin completely inhib- ited age-associated cell death upon PTC6 deletion, suggesting a conserved role of this pathway (Fig. S5A, B). In the absence of the kinase Pkp1, i.e. under Pda1 inhibitory conditions, spartin expression first enhanced ROS production at early time points, but then displayed its usual rescuing

Table 1. Putative interaction partners of spartin revealed by mass spectrometry analysis of immunoprecipitated dSp-FLAG.

\begin{tabular}{|c|c|c|c|c|c|c|}
\hline Sample & Protein & $\begin{array}{c}\text { Dist. } \\
\text { Peptides }\end{array}$ & kDa & Score & Location & Function \\
\hline \multirow[t]{3}{*}{ A } & Ctr9 & 11 & 124.8 & 167.9 & Nucleus & Paf1 complex - histon modification \\
\hline & Pds5 & 2 & 147.0 & 19.8 & Cytosol & Chromosome-associated \\
\hline & Gde1 & 2 & 138.0 & 33.9 & Cytosol & $\begin{array}{l}\text { Glycerophosphocholine (GroPCho) } \\
\text { phosphodiesterase }\end{array}$ \\
\hline \multirow[t]{2}{*}{ B } & Pfk26 & 6 & 93.5 & 95.6 & Cytosol & Regulator of glycolysis \\
\hline & Rpn2 & 2 & 104.3 & 27.7 & Cytosol & Proteasome \\
\hline \multirow[t]{4}{*}{ C } & Spartin (fly) & 4 & 63.0 & 58.4 & & \\
\hline & Hsp/hsc82 & 2 & 81.4 & 31.8 & Cytosol & Mitochondrial-associated chaperon \\
\hline & Atg20 & 2 & 72.5 & 24.0 & Cytosol & Vacuole-associated, cvt pathway \\
\hline & Pfk26 & 11 & 93.5 & 182.0 & Cytosol & Regulator of glycolysis \\
\hline \multirow[t]{5}{*}{ D } & Spartin (fly) & 4 & 63.0 & 290.7 & & \\
\hline & Rtf1 & 3 & 65.9 & 48.0 & Nucleus & Paf1 complex - histone modification \\
\hline & Ssc1 & 5 & 70.8 & 76.6 & Mitochondria & Chaperon \\
\hline & Pfk26 & 3 & 93.5 & 43.1 & Cytosol & Regulator of glycolysis \\
\hline & Ilv2 & 2 & 74.9 & 29.9 & Mitochondria & Isoleucine and valine biosynthesis \\
\hline \multirow[t]{12}{*}{$E$} & Spartin (fly) & 17 & 63.0 & 54.8 & & \\
\hline & Nde1 & 3 & 62.8 & 36.3 & Mitochondria & NADH dehydrogenase \\
\hline & Spartin (fly) & 8 & 63.0 & 150.7 & & \\
\hline & $\mathrm{Cdc73}$ & 4 & 44.5 & 62.6 & Nucleus & Paf1 complex - histone modification \\
\hline & Tef2 & 12 & 50.0 & 185.7 & Cytosol /nucleus & Translation \\
\hline & Tef4 & 2 & 46.5 & 26.5 & Cytosol /nucleus & Translation \\
\hline & $\mathrm{Rpl3}$ & 2 & 43.8 & 33.2 & Cytosol /nucleus & Ribosome \\
\hline & Bio3 & 5 & 53.7 & 84.5 & Cytosol & Biotin biosynthesis \\
\hline & Sam1 & 2 & 41.8 & 33.4 & Cytosol & S-adenosylmethionine synthetase \\
\hline & Rpt6 & 3 & 45.3 & 47.7 & Cytosol & Proteasome \\
\hline & Rpn5 & 3 & 51.8 & 37.5 & Cytosol & Proteasome \\
\hline & Rpn6 & 2 & 49.8 & 28.0 & Cytosol & Proteasome \\
\hline G & Sec4 & 2 & 23.5 & 34.6 & Cytosol & $\begin{array}{l}\text { Vesicle-mediated exocytic secretion } \\
\text { and autophagy }\end{array}$ \\
\hline \multirow{2}{*}{ H } & Spartin (fly) & 2 & 63.0 & 38.9 & & \\
\hline & Rps18ap & 8 & 17.0 & 121.8 & Cytosol /nucleus & Ribosome \\
\hline \multirow[t]{14}{*}{ I } & Rps14 & 6 & 14.7 & 92.3 & Cytosol /nucleus & Ribosome \\
\hline & Rpl26 & 6 & 14.2 & 85.0 & Cytosol /nucleus & Ribosome \\
\hline & Rpl23 & 4 & 14.5 & 71.8 & Cytosol /nucleus & Ribosome \\
\hline & Rps16 & 4 & 15.8 & 68.7 & Cytosol /nucleus & Ribosome \\
\hline & Rps13 & 4 & 17.0 & 58.6 & Cytosol /nucleus & Ribosome \\
\hline & Rps25 & 3 & 12.0 & 48.7 & Cytosol /nucleus & Ribosome \\
\hline & Rps19 & 3 & 15.9 & 44.3 & Cytosol /nucleus & Ribosome \\
\hline & Rpl27ap & 3 & 15.5 & 42.1 & Cytosol /nucleus & Ribosome \\
\hline & Rpl14 & 2 & 15.2 & 35.8 & Cytosol /nucleus & Ribosome \\
\hline & Rps15 & 2 & 16.0 & 35.4 & Cytosol /nucleus & Ribosome \\
\hline & Rps12 & 2 & 15.5 & 33.6 & Cytosol /nucleus & Ribosome \\
\hline & Rpl33 & 2 & 12.2 & 27.0 & Cytosol /nucleus & Ribosome \\
\hline & Rps17 & 1 & 15.8 & 19.6 & Cytosol /nucleus & Ribosome \\
\hline & Yip3 & 4 & 19.4 & 68.3 & Cytosol & $\begin{array}{l}\text { COPII vesicles, involved in ER to Golgi } \\
\text { transport }\end{array}$ \\
\hline
\end{tabular}


A
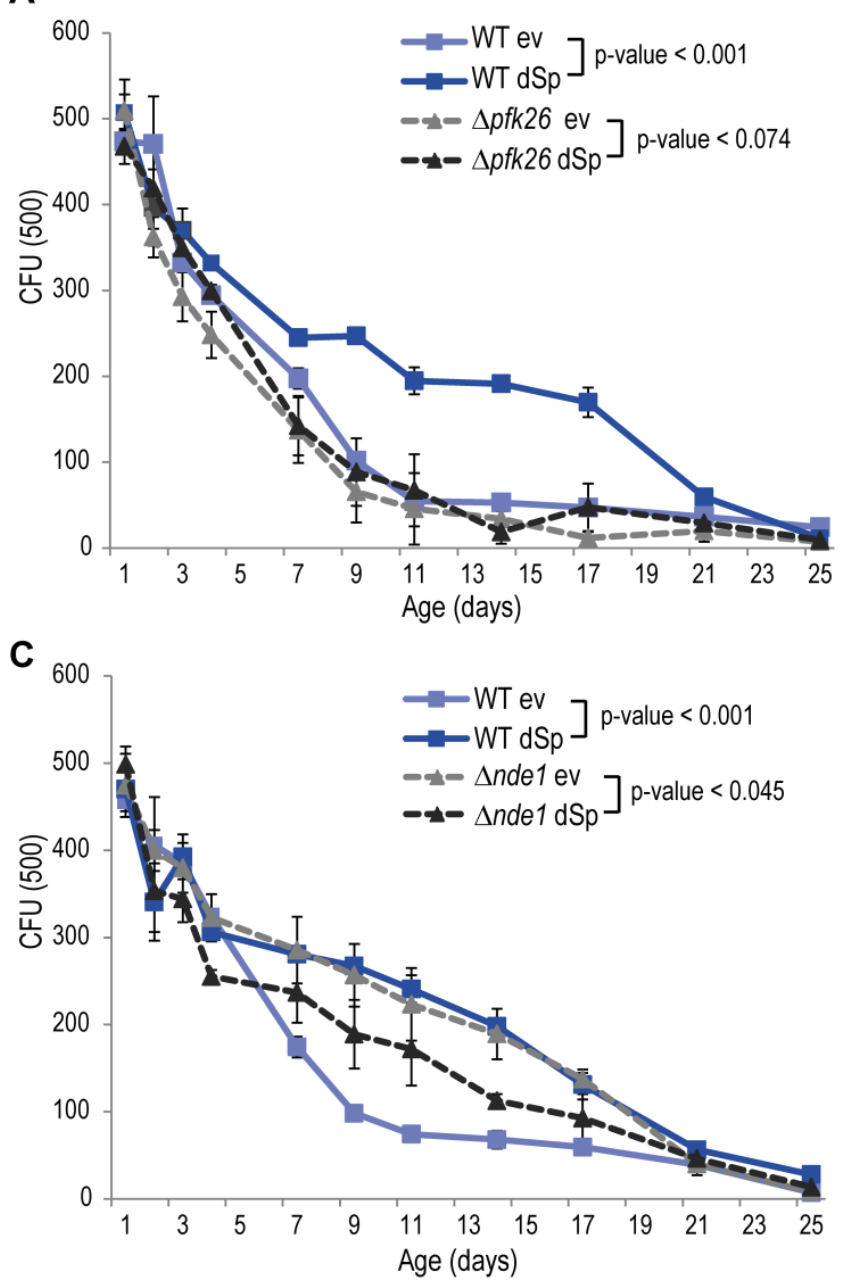

B

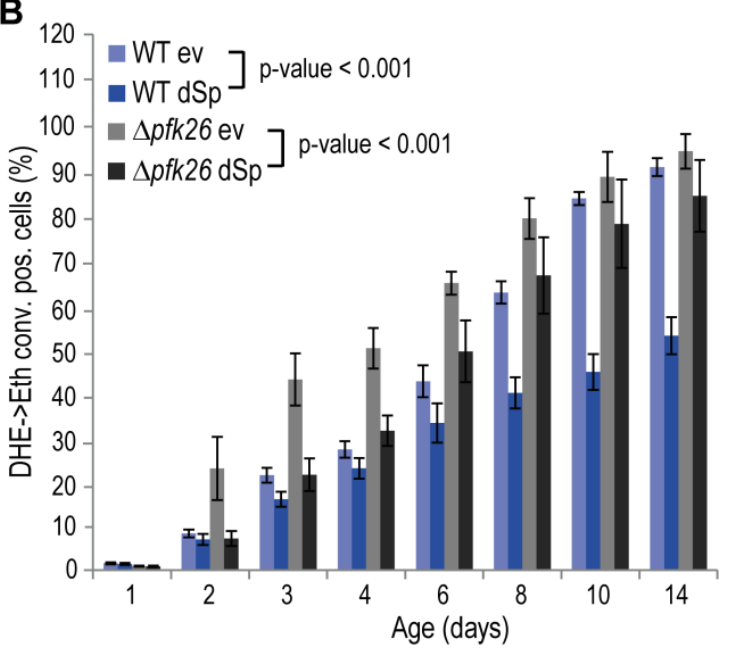

D

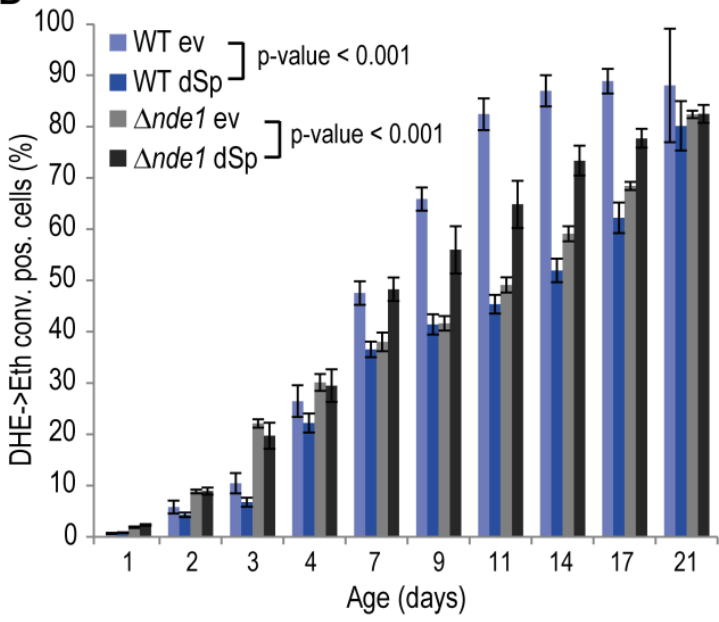

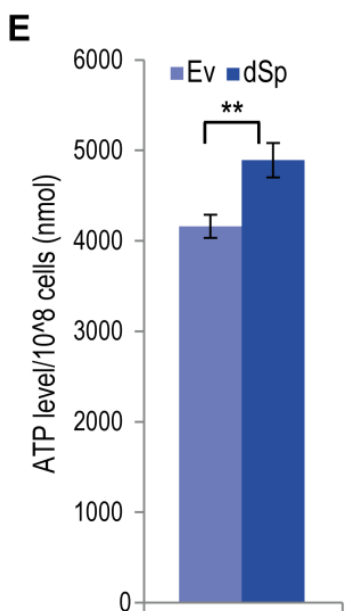

WT

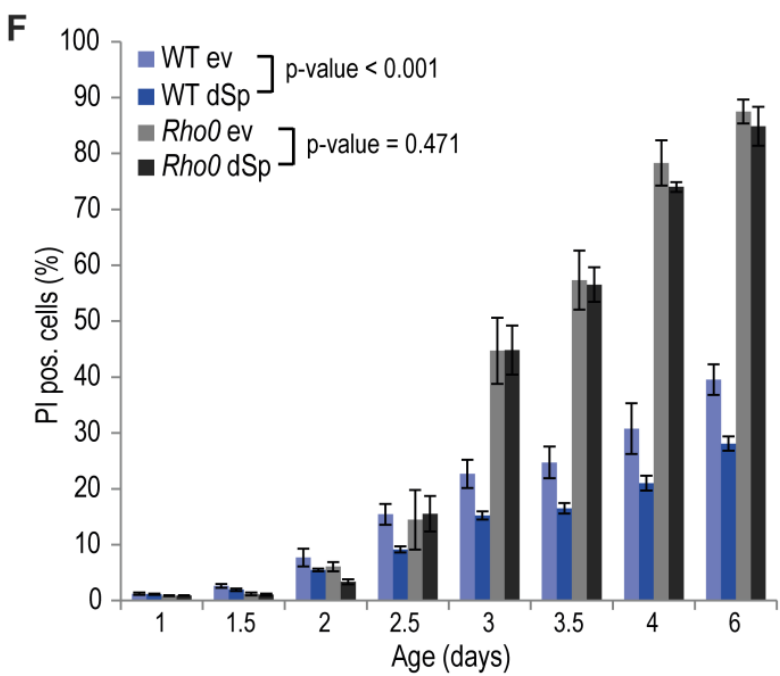

FIGURE 2: The pro-survival function of spartin depends on functional glycolysis and mitochondrial respiration. (A, C) Survival during chronological aging of WT, $\Delta p f k 26$ and $\Delta n d e 1$ cells expressing dSp or cells harboring the corresponding ev. Data represent mean values of at least four independent experiments performed at the same time. CFU, colony-forming unit. Error bars represent standard error of mean (SEM). (B, D) Flow cytometry-assisted quantification of oxidative stress levels (conversion of DHE to Eth). (E) Quantification of ATP levels of WT cells expressing dSp or cells harboring the corresponding ev on day 2 of chronological aging. Data represent mean \pm SEM of three independent experiments. (F) Cell death during chronological aging of WT and rho ${ }^{\circ}$ cells expressing dSp or cells harboring the corresponding ev, quantified by measuring primary and secondary necrotic cells by PI staining, using flow cytometry. Data represent mean \pm SEM of four independent experiments. 
effect later upon aging (Fig. 3E, F). In summary, these data suggest that spartin can promote PDH complex activity as long as the Pda1 core enzyme remains functional.

Besides its function as an activator of the PDH complex, Ptc6 is known to activate mitophagy via induction of the retrograde response [43]. Mitophagy is a mitochondriaspecialized form of macroautophagy, an intracellular degradative process with mostly cytoprotective properties [44] Thus, we tested for a potential connection between this additional role and spartin-mediated cytoprotection. Quantification of the retrograde response by a CIT2 promotor activity assay demonstrated that spartin has no impact on the retrograde response in aging wildtype or $\Delta p t c 6$ cells (Fig. S6A, B). Also the deletion of PTC6 per se did not affect the retrograde response compared to wildtype in our experimental aging conditions (Fig. S6A, B). Of note, these results differ from studies showing an active role of Ptc6 in mitophagy/retrograde response [43, 45]. This discrepancy might be due to differing experimental setups: we used galactose as the carbon source while previous studies used lactate or caffeine, both known to induce mitophagy. Thus, in cells aging on galactose, the lack of Ptc6 causes premature death that is independent of the role of this phosphatase in retrograde response, and expression of spartin can complement for the loss of this vital Ptc6 function(s). Of note, expression levels of dSp were similar in all strains (Fig. S1C).

\section{DISCUSSION}

Mutations in SPG20 lead to loss of function of the protein spartin, which results in Troyer Syndrome. In this study we investigated the role of heterologously expressed Drosophila and human spartin during chronological aging of yeast cells, a model of post-mitotic cellular aging in eukaryotes. Using clonogenicity assays combined with the examination of cell stress markers, we demonstrate that spartin has a pro-survival function. Spartin reduced ROS production and increased lifespan by interacting with and regulating key players of mitochondria-associated metabolism. Previous studies on spartin mainly focused on the characterization of the protein's domains and motifs, interactors and localization as well as on the pathological consequences of its mutations. However, the vital functions of spartin yet remain poorly understood. In this work, we suggest that spartin has important vital functions by improving mitochondria-associated metabolism.

Several lines of evidence suggest that spartin might be functionally associated with mitochondria, a central organelle for metabolism and cell death control. In fact, spartin has been shown to translocate to mitochondria $[15-17,46]$ Cells with decreased spartin levels display abnormal mitochondrial morphology and mobility as well as a reduction of mitochondrial membrane potential and calcium uptake $[15,46]$. Recently, muscle biopsy of patients with mutated SPG20 revealed reduced cytochrome c oxidase (COX) activity leading to decreased oxidative phosphorylation [6]. Interestingly, another HSP-associated gene, SPG7, which codes for the metalloproteinase paraplegin, is part of a complex in the inner mitochondrial membrane. Absence of SPG7 leads to reduced complex I activity and decreased stress tolerance in humans [47]. Further, muscle biopsies of HSP patients with mutated SPG7 show defects in mitochondrial oxidative phosphorylation [47]. Still, the possibility and nature of a putative mitochondrial function of spartin remains unclear.

Using fluorescence microscopy as well as pulldown analysis, we have discovered that a certain amount of spartin localizes to the proximity of mitochondria and interacts with mitochondrial proteins in yeast. For instance, we identified the mitochondrial external NADH dehydrogenase, Nde1, as a potential interactor of spartin. Nde1 is part of a supercomplex that replaces complex $I$ in yeast and provides cytosolic NADH to the mitochondrial respiratory chain [48]. In $\Delta$ nde1 cells, spartin failed to display its prosurvival function, suggesting that spartin's interaction with Nde1 is crucial for its beneficial effects on cell survival. In addition, we found the cytosolic glycolytic flux-enhancing phospho-fructo-kinase Pfk26 to interact with spartin. Our results further show that spartin's vital functions partly depend on this interactor. Interestingly, spartin can prevent ROS accumulation in the absence of Pfk26 only during early aging. Thus, different pathways might be influenced at different stages of the aging process, which remains to be elucidated. Finally, we also found that mitochondriaassociated chaperones (i.e. Ssc1 and Hsp82/Hsc82) copurify with spartin. This is in line with published data, showing that spartin interacts with a human mitochondrial Hsp70 (Grp75) [17]. Interestingly, the Grp75 yeast homolog (Ssq1) cooperates with yeast Ssc1 [49]. Given that mitochondrial chaperones are important for protein import and maturation of certain mitochondrial complexes, these chaperones might be directly linked to the mitochondriaassociated vital functions of spartin. Such dependency needs to be mechanistically elucidated in future work.

Given the impact of spartin on mitochondria, we tested spartin's effects in the absence of Pda1, a core enzyme of the PDH complex, which in turn is necessary for mitochondrial import of pyruvate to feed into oxidative phosphorylation and thus links glycolysis to mitochondrial energy metabolism. The pro-survival effect of spartin was lost in Pda1-deficient cells. Interestingly, the rescuing effect became even more pronounced in cells lacking Ptc6, an activator of the PDH complex. Also the absence of the PDHinhibitory kinase Pkp1 did not abolish the rescuing effects of spartin. Thus, the effects of spartin rather rely on the core catalytic subunit of the PDH complex (Pda1) than on its known regulators. Whether the actual PDH activity is modulated by spartin directly or via indirect alternative routes remains to be analyzed.

Nde1 as well as the PDH complex link cytosolic glycolysis to mitochondria. In fact, we show here that spartin increases ATP production and depends on intact mitochondria to exert its vital functions (Fig. 4). This goes in line with the current literature. For instance, enhanced respiration has been demonstrated to act cytoprotectively in neurodegenerative settings [50]. Nde1 and the PDH complex 

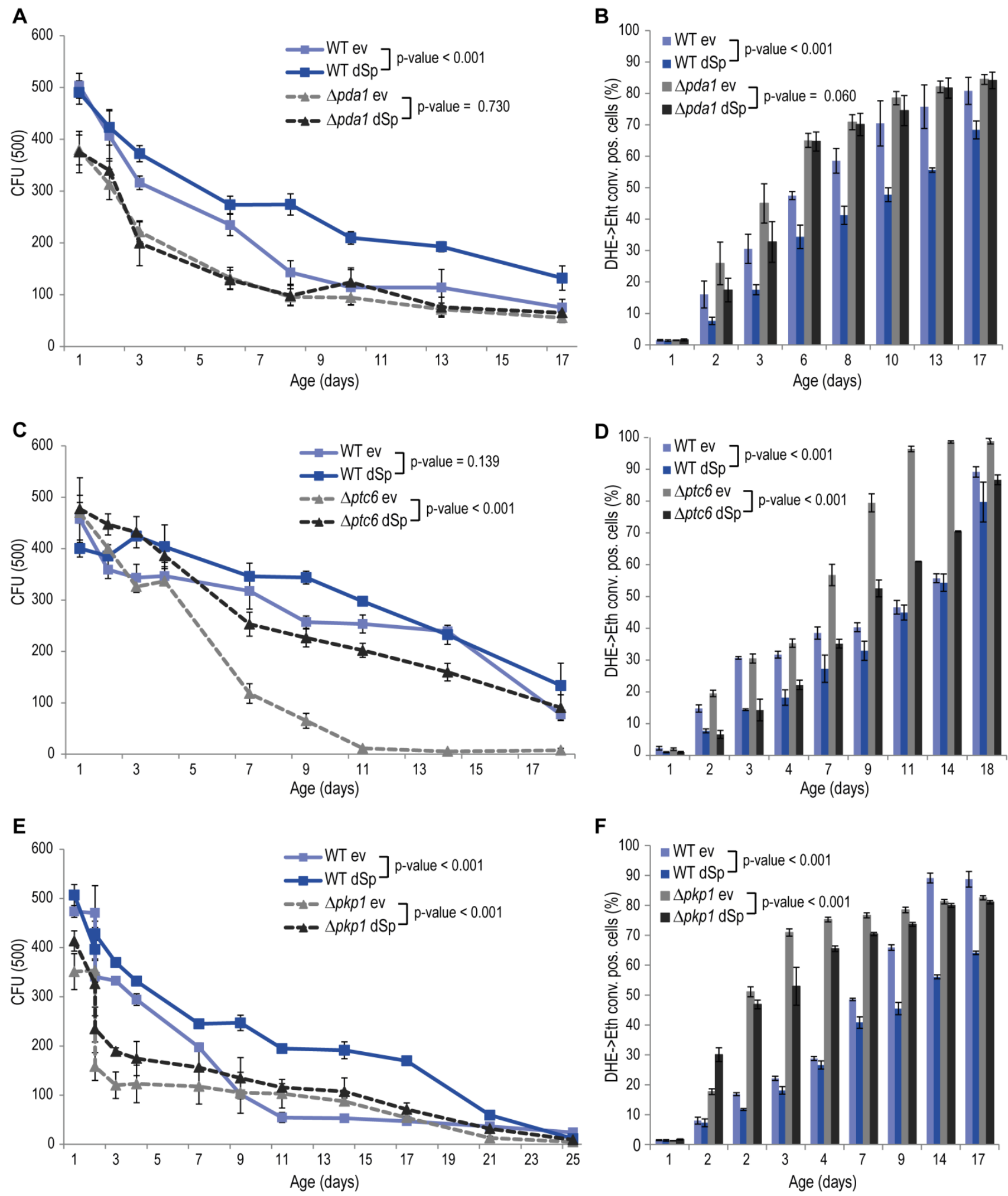

FIGURE 3: Spartin requires pyruvate dehydrogenase (PDH) complex activity for cell death protection in aging. (A, C, E) Survival during chronological aging of WT, $\Delta p d a 1, \Delta p t c 6$ or $\Delta p k p 1$ cells expressing dSp or cells harboring the corresponding ev. Data represent mean \pm SEM of four independent experiments. CFU, colony-forming units. (B, D, F) Quantification of oxidative stress levels (conversion of DHE to Eth) quantified by flow cytometry. 
might function as a metabolic regulation handle controlled by spartin. Highly active Nde1 and PDH decrease both $\mathrm{NADH}$ and pyruvate levels in the cytosol, which simultaneously increase respiration and glycolysis [51]. Additionally, Pfk26 is the known positive regulator of glycolytic flux and might be influenced by its interaction with spartin. Thus, one of the primary functions of spartin could reside in the regulation of glycolytic to mitochondrial respirationassociated metabolic flux via interaction at several check points.

Besides its basic function in the mitochondrial respiratory chain, $\mathrm{NAD}^{+} / \mathrm{NADH}$ metabolism is also part of metabolic adaptations known to influence aging, cell death and oxidative stress. For instance, the $\mathrm{NAD}^{+} / \mathrm{NADH}$ equilibrium between cytosol and mitochondria determines the longevity effect in response to caloric restriction (CR) [52]. Notably, CR-induced longevity also depends on actively respiring mitochondria [53]. Moreover, an imbalance of the cytosolic $\mathrm{NAD}^{+} / \mathrm{NADH}$ ratio due to the dysregulation of the glycolytic metabolic network has been linked to several diseases, including cancer [54]. Intriguingly, another study proposed spartin as a biomarker in certain types of cancer, in which hypermethylation of SPG2O and thus downregulation of spartin expression correlates with tumorigenesis $[7,8]$. This might be associated with the Warburg effect, by which cancer cells shift their metabolism from mitochondrial respiration to aerobic glycolysis [55]. Finally, neurons highly rely on mitochondrial respiration to serve their energy needs, which is accompanied by low levels of glycolysis. Interestingly, spartin seems to be able to control all key regulators in this metabolic adaption processes. Pfk26 is the key regulator of glycolytic flux, whereas Nde1 and PDH are the bottlenecks to serve mitochondrial respiration.

Our study supports the assumption and adds evidence to the hypothesis that mitochondrial dysfunction is crucial in the pathogenesis of Troyer Syndrome. Moreover, it shows that spartin is an important key regulator of longevity-associated metabolic status of the cell, which needs further investigation in future research.

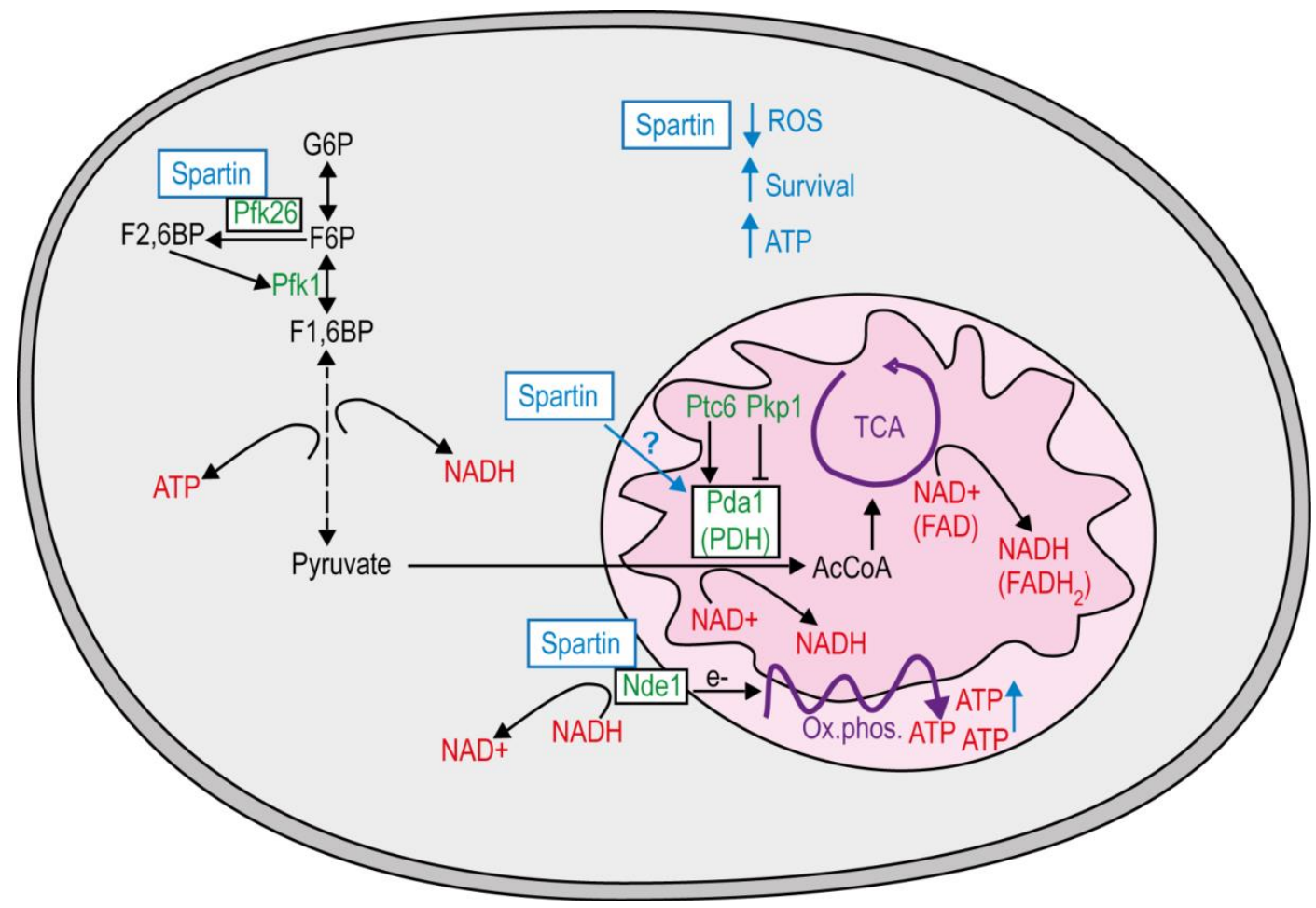

FIGURE 4: Model of how spartin modulates mitochondrial energy metabolism. Spartin has a pro-survival effect in chronological aging yeast and requires key regulators in energy metabolism. Spartin interacts with the cytosolic glycolytic flux-enhancing phospho-fructo-kinase Pfk26 and partly depends on Pfk26 to promote longevity, possibly by regulating the availability of NADH and pyruvate for also mitochondrial metabolism. The mitochondrial external NADH dehydrogenase Nde1 oxidizes NADH to transfer electrons to complex II and thus promotes oxidative phosphorylation to produce ATP. Spartin interacts with Nde1 and fails to exert its pro-survival role in $\Delta$ nde1 cells. The pyruvate dehydrogenase (PDH) complex converts pyruvate to acetyl-CoA (AcCoA), which feeds the tricarboxylic acid (TCA) cycle to produce NADH and $\mathrm{FADH}_{2}$ serving again ATP production through oxidative phosphorylation. Pda1, the core enzyme of the PDH complex can be activated by phosphorylation through the phosphatase Ptc6 and inactivated by Pkp1 kinase. In the absence of Pda1 spartin does not promote longevity, but it can completely complement cell death due deletion of PTC6 and therefore mimics Ptc6 function. Whether spartin directly or indirectly (through associated metabolism) modulates PDH to promote cell survival remains to be investigates, In the presence of spartin cells may thus produce more ATP due to optimized oxidative phosphorylation. G6P, glucose-6-phophate. F2,6BP, fructose-2,6-biphosphate. F6P, fructose-6-phosphate. Pfk1, Phosphofructokinase 1. F1,6BP, fructose-1,6-biphophate. 


\section{MATERIALS AND METHODS}

\section{Yeast strains, plasmids and media}

Experiments were carried out in BY4741 wild type (MATa his $3 \Delta 1$ leu2 $\Delta 0$ met $15 \Delta 0$ ura3 $\Delta 0$ ) and corresponding null mutants from the EUROSCARF strain collection $\Delta$ nde1, $\Delta p f k 26$, $\Delta p d a 1, \Delta p k p 1, \Delta p t c 6$ and $\Delta r t g 2$, as well as in $r 0^{\circ}$ cells, lacking mitochondrial DNA [29]. Gene expression was under the control of galactose-regulated promoters and therefore strains were precultured on SC medium containing $0.17 \%$ yeast nitrogen base (Difco, BD Biosciences, Schwechat, Austria), 0.5\% $\left(\mathrm{NH}_{4}\right)_{2} \mathrm{SO}_{4}$ and $30 \mathrm{mg} / \mathrm{l}$ of all amino acids (except $80 \mathrm{mg} / \mathrm{l}$ histidine and $200 \mathrm{mg} / \mathrm{l}$ leucine), $30 \mathrm{mg} / \mathrm{l}$ adenine and $320 \mathrm{mg} / \mathrm{l}$ uracil with $2 \%$ glucose $(S C D)$ and respectably shifted to $2 \%$ galactose (SCG). All amino acids were purchased from Serva (research grade, $\geq 98.5 \%$ ). Transformation was done using the lithium acetate method [56]. Notably, at least three different clones were tested in each experiment, to rule out clonogenic variation. For heterologous expression of Drosophila or human spartin, genes were amplified by PCR from respective CDNA and inserted into $\mathrm{pESC}$-HIS vector from Stratagene (galactose promotor and c-terminal FLAG-tag) or pUG35-URA vector (methionine-repressible promoter and c-terminal GFP-tag) for microscopy. For Drosophila spartin (dSp) primers 3'-ATC TAC TAG T AT GGC GGA GGA GGA AAG C-5' and 3'-ATC TAT CGA TTT CCT TCA AAG CTC GAA GAT CCG-5' (pUG35-URA) or 3'ATC T AT CGA TGT TTC CTT CAA AGC TCG AAG ATC CG-5' (pESC-HIS), for human spartin (hSp) primers $3^{\prime}$-ATC TGA ATT CAT GGA GCA AGA GCC ACA AAA TG-5' and 3'-ATC TGA ATT CTT TAT CTT TCT TCT TTG CCT CCT TTA CTT CC-5' (pUG35URA) or 3'-ATC TGC GGC CGC TTT ATC TTT CTT CTT TGC CTC CTT TAC TTC C-5' (pESC-HIS) were used. Resulting plasmids were verified by sequencing by eurofins/MWG and expression was verified by immunoblot analysis. For mitochondrial colocalization studies cells additionally harbored plasmid, expressing dsRed with a mitochondrial localization sequence constitutively (pFM123-LEU mito dsRed).

\section{S. cerevisiae immunoblot analysis}

To verify proper and equal expression of comparing strains we harvesting an aliquot (3.5 OD) of cells cultured for the chronological aging experiments, 20 hours after shift to expression media (SCG). Preparation of cell extracts and immunoblotting were performed as described [42]. Soluble proteins were separated on Tricine-SDS polyacrylamide gels with an acrylamide concentration of $12,5 \%$, transferred on Polyvinylidendifluorid (PVDF) membranes, and probed with murine monoclonal antibodies against FLAG-epitope (Sigma), murine monoclonal antibodies against glyceraldehyde-3-phosphate dehydrogenase (kind gift from Günther Daum) and the respective peroxidase-conjugated affinity-purified secondary antibody (AntiMouse IgG-Peroxidase antibody A9044, Sigma). For detection the ECL system was used (Amersham). Immunodetection was done using luminol. Membranes were digitized in ChemiDoc ${ }^{\text {TM }}$ Touch Imaging System (BIO RAD).

\section{Chronological aging, clonogenictiy, and test for stress and cell death markers}

For chronological aging experiments cells were inoculated in SCD media to an $\mathrm{OD}_{600}$ of 0.05 and cultured at $28^{\circ} \mathrm{C}$ and shaking at $145 \mathrm{rpm}$. Cells containing the $\mathrm{pESC}-\mathrm{HIS}$ vector were after grown for 4.5 hours to an $\mathrm{OD}_{600}$ of $0.15-0.2$ then shifted to expression media containing galactose (SCG). At indicated time points cell survival was determined by clonogenictiy. Therefore cell cultures were counted with a CASY cell counter (Schärfe System) and 500 cells were plated on YPD agar plates ( $2 \%$ peptone, $1 \%$ yeast extract, $2 \%$ glucose, and $2 \%$ agar) and incubated for 2 to 3 days at $28^{\circ} \mathrm{C}$. Subsequently colony forming units were counted using an automated colony counter. Additionally, oxidative stress was determined by measuring the conversion of dihydroethidium (DHE, Sigma-Aldrich) to the red fluorescent ethidium and subsequent flow cytometry analysis (BD FACSAria). Cell death was measured via propidium iodide (PI, Sigma-Aldrich) staining in cells that have lost their plasma membrane integrity and quantified with flow cytometry analysis. Further, Annexin V/PI co-staining (Annexin V-FLUOS Staining Kit, Roche Applied Science) was used at indicated time points and quantified with flow cytometry analysis to distinguish between early apoptotic (Annexin $\mathrm{V}$ positive), late apoptotic (secondary necrotic, double positive), as well as necrotic cells (only PI positive) cells. 30,000 cells per sample were evaluated using BD FACSDiva software. Representative aging analyses are shown with at least three independent cultures aged at the same time. All aging analyses were performed at least twice in total with similar outcome.

\section{Microscopy}

Microscopy of GFP expressing cells was performed with a Zeiss Axioskop microscope using a Zeiss Plan-Neofluar objective lens with $63 \times$ magnification and 1.25 numerical apertures in oil (using Zeiss Immersol) at room temperature. Fluorescence microscopic sample images were taken with a Diagnostic Instruments camera (Model: SPOT 9.0 Monochrome-6), acquired and processed (coloring) using the Metamorph software (version 6.2r4, Universal Imaging Corp.) Mitochondria were visualized by co expression of mitochondrial-targeted dsRed ( $p F M 123-L E U)$.

\section{Quantification of ATP levels}

To determine the ATP level of yeast cultures, intracellular metabolites were obtained using hot ethanol extraction. ATP was measured using the ATP Determination Kit (Molecular Probes, Life Technologies). This assay is based on an ATPdependent reaction of recombinant firefly luciferase, which induces bioluminescence of its substrate D-luciferin and is directly correlated with the ATP content. The luminescence was measured at a GloMax. Data analysis was performed with Microsoft Excel and Graphpad Prism. All data were normalized to the number of living cells within the samples.

\section{Quantification of retrograde response}

Retrograde response (RTG) was monitored by CIT2 promotor activity [57]. Strains were transformed with and selected for plasmid pCG479 containing lacZ under the control of the CIT2promotor (kind gift from Gourlay Campbell). Briefly $1 \times 10^{7}$ cells were harvested and resuspended in Z-buffer $(0.06 \mathrm{M}$ $\mathrm{Na}_{2} \mathrm{HPO}_{4} * 7 \mathrm{H}_{2} \mathrm{O}, 0.04 \mathrm{M} \mathrm{Na}_{2} \mathrm{H}_{2} \mathrm{PO}_{4} * 2 \mathrm{H}_{2} \mathrm{O}, 0.01 \mathrm{M} \mathrm{KCl}, 0.0001$ $\mathrm{MgSO}_{4}, \mathrm{pH} 7.0$ ) and $2.5 \mathrm{mM}$ beta-mercaptoethanol. With an aliqout of this suspension $\mathrm{OD}_{600}$ was measured on the GENiosPro 96-well fluorescence plate reader (Tecan, Grödig, Austria). Cells for the assay were vortext for 30 seconds containing additional SDS with final concentration of $0.01 \%$ and $10 \%$ $\mathrm{CHCl}_{3}$. For the reaction $220 \mu \mathrm{g}$ ONPG (in Z-buffer solution) was added as substrate and incubated until solution got yellowish. Time was noted and the reaction was stopped with $250 \mathrm{mM}$ 
$\mathrm{Na}_{2} \mathrm{CO}_{3}$. An aliqout of the water-phase was measured on the Tecan at $\mathrm{OD}_{405}$. For calculating RTG activity RFU of $\mathrm{OD}_{405}$ was normalized on incubation time and $\mathrm{OD}_{600}$.

\section{Pulldown assay and LC-MS/MS analysis}

Whole-cell extracts of cells expressing FLAG-tagged Drosophila spartin or cells harboring the corresponding vector control were lysed and subjected to pulldown analysis using agarose beads coupled to monoclonal anti-FLAG antibody (Anti-FlagTm M2 affinity gel, Sigma). Subsequent eluates were separated by SDS-PAGE using Tricine-SDS polyacrylamide gels. The gel lanes were cut into slices, which were in-gel digested with trypsin (Promega), and the resulting peptide mixtures were analyzed by LC-MS/MS. For detailed information see [58].

\section{ACKNOWLEDGEMENTS}

FM is grateful to the Austrian Science Fund FWF (Austria) for grants, P29262, P29203 P27893, and 'SFB Lipotox' (F3012), grant DK Metabolic and Cardiovascular Diseases (W 1226) funded by the FWF to J.T. and F.M. as well as to BMWFW and the Karl-Franzens University for grants 'Unkonventionelle Forschung' and flysleep. FM acknowledges support from NAWI Graz and the BioTechMed-Graz flagship project "EPIAge". PR is an Erwin Schrödinger research fellow of the Austrian Science Fund FWF (J3742-B28). T.E. is a recipient of an APART fellowship of the Austrian Academy of Sciences at the Institute of Molecular Biosciences, University of Graz. Thanks to Campbell Gourlay to provide the plasmid pCG479-CIT2-LacZ for retrograde response quantification and Günther Daum for antibodies. GK is supported by the Ligue contre le Cancer Comité de Charente-Maritime (équipe labelisée); Agence National de la Recherche (ANR) - Projets blancs; ANR under the frame of E-Rare-2, the ERA-Net for Research on Rare Diseases; Association pour la recherche sur le cancer (ARC); Cancéropôle Ile-de-France; Chancelerie des universités de Paris (Legs Poix), Fondation pour la Recherche Médicale (FRM); the European Commission (ArtForce); the European Research

\section{REFERENCES}

1. Bakowska JC, Wang H, Xin B, Sumner CJ, and Blackstone C (2008). Lack of spartin protein in Troyer syndrome: a loss-of-function disease mechanism? Arch Neurol 65(4): 520-524.

2. Bizzari S, Hamzeh AR, Nair P, Mohamed M, Saif F, Aithala G, Al-Ali MT, and Bastaki F (2017). Novel SPG20 mutation in an extended family with Troyer syndrome. Metab Brain Dis 32(6): 2155-2159.

3. Butler S, Helbig KL, Alcaraz W, Seaver LH, Hsieh DT, and Rohena L (2016). Three cases of Troyer syndrome in two families of Filipino descent. Am J Med Genet A 170(7): 1780-1785.

4. Dardour L, Roelens F, Race V, Souche E, Holvoet M, and Devriendt K (2017). SPG20 mutation in three siblings with familial hereditary spastic paraplegia. Cold Spring Harb Mol Case Stud 3(4).

5. Patel $H$, Cross $H$, Proukakis $C$, Hershberger R, Bork P, Ciccarelli FD, Patton MA, McKusick VA, and Crosby AH (2002). SPG20 is mutated in Troyer syndrome, an hereditary spastic paraplegia. Nat Genet 31(4): 347-348.

6. Spiegel R, Soiferman D, Shaag A, Shalev S, Elpeleg O, and Saada A (2017). Novel Homozygous Missense Mutation in SPG20 Gene Results
Council (ERC); Fondation Carrefour; Institut National du Cancer (INCa); Inserm (HTE); Institut Universitaire de France; LeDucq Foundation; the LabEx Immuno-Oncology; the RHU Torino Lumière, the Searave Foundation; the SIRIC Stratified Oncology Cell DNA Repair and Tumor Immune Elimination (SOCRATE); the SIRIC Cancer Research and Personalized Medicine (CARPEM); and the Paris Alliance of Cancer Research Institutes (PACRI). SB was supported by the Austrian Science Fund FWF (P27183-B24), the Swedish Research Council Vetenskapsrådet (2015-05468), Åke Wiberg Stifelse (M16-0130), and Carl Trygger Stiflese (CTS16:85).

\section{SUPPLEMENTAL MATERIAL}

All supplemental data for this article are available online at www.microbialcell.com.

\section{CONFLICT OF INTEREST}

The authors declare no conflict of interest.

\section{COPYRIGHT}

(C) 2017 Ring et al. This is an open-access article released under the terms of the Creative Commons Attribution (CC BY) license, which allows the unrestricted use, distribution, and reproduction in any medium, provided the original author and source are acknowledged.

Please cite this article as: Julia Ring, Patrick Rockenfeller, Claudia Abraham, Jelena Tadic, Michael Poglitsc, Katherina Schimmel, Julia Westermayer, Simon Schauer, Bettina Achleitner, Christa Schimpel, Barbara Moitzi, Gerald N. Rechberger, Stephan J. Sigrist, Didac Carmona-Gutierrez, Guido Kroemer, Sabrina Büttner, Tobias Eisenberg, Frank Madeo (2017). Mitochondrial energy metabolism is required for lifespan extension by the spastic paraplegiaassociated protein spartin. Microbial Cell 4(12): 411-422. doi: 10.15698/mic2017.12.603

in Troyer Syndrome Associated with Mitochondrial Cytochrome c Oxidase Deficiency. JIMD Rep 33: 55-60.

7. Lind GE, Raiborg C, Danielsen SA, Rognum TO, Thiis-Evensen E, Hoff G, Nesbakken A, Stenmark H, and Lothe RA (2011). SPG20, a novel biomarker for early detection of colorectal cancer, encodes a regulator of cytokinesis. Oncogene 30(37): 3967-3978.

8. Zhang $H$, Song $Y$, Xia $P$, Cheng $Y$, Guo $Q$, Diao D, Wang W, Wu X, Liu $D$, and Dang C (2014). Detection of aberrant hypermethylated spastic paraplegia-20 as a potential biomarker and prognostic factor in gastric cancer. Med Oncol Northwood Lond Engl 31(2): 830.

9. Ciccarelli FD, Proukakis C, Patel H, Cross H, Azam S, Patton MA, Bork $P$, and Crosby $\mathrm{AH}$ (2003). The identification of a conserved domain in both spartin and spastin, mutated in hereditary spastic paraplegia. Genomics 81(4): 437-441. 12676568.

10. Eastman SW, Yassaee M, and Bieniasz PD (2009). A role for ubiquitin ligases and Spartin/SPG20 in lipid droplet turnover. J Cell Biol 184(6): 881-894. 
11. Karlsson AB, Washington J, Dimitrova V, Hooper C, Shekhtman A, and Bakowska JC (2014). The role of spartin and its novel ubiquitin binding region in DALIS occurrence. Mol Biol Cell 25(8): 1355-1365.

12. Bakowska JC, Jupille $H$, Fatheddin $P$, Puertollano R, and Blackstone $C$ (2007). Troyer syndrome protein spartin is mono-ubiquitinated and functions in EGF receptor trafficking. Mol Biol Cell 18(5): 1683-1692.

13. Edwards TL, Clowes VE, Tsang HTH, Connell JW, Sanderson CM, Luzio JP, and Reid E (2009). Endogenous spartin (SPG20) is recruited to endosomes and lipid droplets and interacts with the ubiquitin E3 ligases AIP4 and AIP5. Biochem J 423(1): 31-39.

14. Gey U, Czupalla C, Hoflack B, Rödel G, and Krause-Buchholz U (2008). Yeast pyruvate dehydrogenase complex is regulated by a concerted activity of two kinases and two phosphatases. J Biol Chem 283(15): 9759-9767.

15. Joshi DC, and Bakowska JC (2011). SPG20 protein spartin associates with cardiolipin via its plant-related senescence domain and regulates mitochondrial Ca2+ homeostasis. PloS One 6(4): e19290.

16. Lu J, Rashid F, and Byrne PC (2006). The hereditary spastic paraplegia protein spartin localises to mitochondria. J Neurochem $98(6)$ 1908-1919.

17. Milewska M, McRedmond J, and Byrne PC (2009). Identification of novel spartin-interactors shows spartin is a multifunctional protein. $J$ Neurochem 111(4): 1022-1030.

18. Renvoisé B, Parker RL, Yang D, Bakowska JC, Hurley JH, and Blackstone $C$ (2010). SPG20 protein spartin is recruited to midbodies by ESCRT-III protein Ist1 and participates in cytokinesis. Mol Biol Cell 21(19): 3293-3303.

19. Robay D, Patel H, Simpson MA, Brown NA, and Crosby AH (2006). Endogenous spartin, mutated in hereditary spastic paraplegia, has a complex subcellular localization suggesting diverse roles in neurons. Exp Cell Res 312(15): 2764-2777.

20. Winner B, Gross C, Uyanik G, Schulte-Mattler W, Lürding R, Marienhagen J, Bogdahn $U$, Windpassinger $C$, Hehr $U$, and Winkler J (2006). Thin corpus callosum and amyotrophy in spastic paraplegia-case report and review of literature. Clin Neurol Neurosurg 108(7): 692-698.

21. Nahm M, Lee M-J, Parkinson W, Lee M, Kim H, Kim Y-J, Kim S, Cho YS, Min B-M, Bae YC, Broadie K, and Lee $S$ (2013). Spartin regulates synaptic growth and neuronal survival by inhibiting BMP-mediated microtubule stabilization. Neuron 77(4): 680-695.

22. Renvoisé B, Stadler J, Singh R, Bakowska JC, and Blackstone C (2012). Spg20-/- mice reveal multimodal functions for Troyer syndrome protein spartin in lipid droplet maintenance, cytokinesis and BMP signaling. Hum Mol Genet 21(16): 3604-3618.

23. Tsang HTH, Edwards TL, Wang X, Connell JW, Davies RJ, Durrington HJ, O'Kane CJ, Luzio JP, and Reid E (2009). The hereditary spastic paraplegia proteins NIPA1, spastin and spartin are inhibitors of mammalian BMP signalling. Hum Mol Genet 18(20): 3805-3821.

24. Zhao J, and Hedera P (2013). Hereditary spastic paraplegia-causing mutations in atlastin-1 interfere with BMPRII trafficking. Mol Cell Neurosci 52: 87-96.

25. Hooper C, Puttamadappa SS, Loring Z, Shekhtman A, and Bakowska JC (2010). Spartin activates atrophin-1-interacting protein 4 (AIP4) E3 ubiquitin ligase and promotes ubiquitination of adipophilin on lipid droplets. BMC Biol 8: 72.

26. Truong T, Karlinski ZA, O’Hara C, Cabe M, Kim H, and Bakowska JC (2015). Oxidative Stress in Caenorhabditis elegans: Protective Effects of Spartin. PloS One 10(6): e0130455.
27. Braun RJ, Büttner S, Ring J, Kroemer G, and Madeo F (2010). Nervous yeast: modeling neurotoxic cell death. Trends Biochem Sci 35(3): 135-144.

28. Braun RJ, Sommer C, Carmona-Gutierrez D, Khoury CM, Ring J, Büttner S, and Madeo $F$ (2011). Neurotoxic 43-kDa TAR DNA-binding protein (TDP-43) triggers mitochondrion-dependent programmed cell death in yeast. J Biol Chem 286(22): 19958-19972.

29. Büttner $S$, Bitto $A$, Ring J, Augsten $M$, Zabrocki $P$, Eisenberg $T$, Jungwirth $\mathrm{H}$, Hutter S, Carmona-Gutierrez D, Kroemer G, Winderickx J, and Madeo $F$ (2008). Functional mitochondria are required for alphasynuclein toxicity in aging yeast. J Biol Chem 283(12): 7554-7560.

30. Heinisch JJ, and Brandt R (2016). Signaling pathways and posttranslational modifications of tau in Alzheimer's disease: the humanization of yeast cells. Microb Cell 3(4): 135-146.

31. Menezes R, Tenreiro S, Macedo D, Santos CN, and Outeiro TF (2015). From the baker to the bedside: yeast models of Parkinson's disease. Microb Cell 2(8): 262-279.

32. Shrestha A, and Megeney LA (2015). Yeast proteinopathy models: a robust tool for deciphering the basis of neurodegeneration. Microb Cell 2(12): 458-465.

33. Treusch S, Hamamichi S, Goodman JL, Matlack KES, Chung CY, Baru V, Shulman JM, Parrado A, Bevis BJ, Valastyan JS, Han H, LindhagenPersson $M$, Reiman EM, Evans DA, Bennett DA, Olofsson A, DeJager $\mathrm{PL}$, Tanzi RE, Caldwell KA, Caldwell GA, and Lindquist $S$ (2011). Functional links between $A \beta$ toxicity, endocytic trafficking, and Alzheimer's disease risk factors in yeast. Science 334(6060): 1241-1245.

34. Büttner S, Eisenberg T, Herker E, Carmona-Gutierrez D, Kroemer G, and Madeo $F(2006)$. Why yeast cells can undergo apoptosis: death in times of peace, love, and war. J Cell Biolm 175(4): 521-525.

35. Carmona-Gutierrez D, Eisenberg T, Büttner S, Meisinger C, Kroemer $G$, and Madeo $F(\mathbf{2 0 1 0})$. Apoptosis in yeast: triggers, pathways, subroutines. Cell Death Differ 17(5): 763-773.

36. Eisenberg T, Carmona-Gutierrez D, Büttner S, Tavernarakis N, and Madeo F (2010). Necrosis in yeast. Apoptosis Int J Program Cell Death 15(3): 257-268.

37. Eisenberg T, Büttner S, Kroemer G, and Madeo F (2007). The mitochondrial pathway in yeast apoptosis. Apoptosis Int J Program Cell Death 12(5): 1011-1023.

38. Galluzzi L, Kepp O, and Kroemer G (2016). Mitochondrial regulation of cell death: a phylogenetically conserved control. Microb Cell 3(3): 101-108.

39. Ring J, Sommer C, Carmona-Gutierrez D, Ruckenstuhl C, Eisenberg $\mathrm{T}$, and Madeo $\mathrm{F}$ (2012). The metabolism beyond programmed cell death in yeast. Exp Cell Res 318(11): 1193-1200.

40. Büttner $S$, Eisenberg $T$, Carmona-Gutierrez $D$, Ruli $D$, Knauer $H_{\text {, }}$ Ruckenstuhl C, Sigrist C, Wissing S, Kollroser M, Fröhlich K-U, Sigrist S, and Madeo $F$ (2007). Endonuclease $G$ regulates budding yeast life and death. Mol Cell 25(2): 233-246.

41. Madeo F, Fröhlich E, Ligr M, Grey M, Sigrist SJ, Wolf DH, and Fröhlich KU (1999). Oxygen stress: a regulator of apoptosis in yeast. J Cell Biol 145(4): 757-767. 10330404.

42. Herker $E$, Jungwirth $H$, Lehmann KA, Maldener C, Fröhlich K-U, Wissing S, Büttner S, Fehr M, Sigrist S, and Madeo F (2004). Chronological aging leads to apoptosis in yeast. J Cell Biol 164(4): 501-507.

43. Journo D, Mor A, and Abeliovich H (2009). Aup1-mediated regulation of Rtg3 during mitophagy. J Biol Chem 284(51): 35885-35895.

44. Yin Z, Pascual C, and Klionsky DJ (2016). Autophagy: machinery and regulation. Microb Cell Graz Austria 3(12): 588-596. 
45. Tal R, Winter G, Ecker N, Klionsky DJ, and Abeliovich H (2007). Aup1p, a Yeast Mitochondrial Protein Phosphatase Homolog, Is Required for Efficient Stationary Phase Mitophagy and Cell Survival. J Biol Chem 282(8): 5617-5624.

46. Milewska M, and Byrne PC (2015). Different expression levels of spartin cause broad spectrum of cellular consequences in human neuroblastoma cells. Cell Biol Int 39(9): 1007-1015.

47. Atorino L, Silvestri L, Koppen M, Cassina L, Ballabio A, Marconi R, Langer $T$, and Casari $G$ (2003). Loss of m-AAA protease in mitochondria causes complex I deficiency and increased sensitivity to oxidative stress in hereditary spastic paraplegia. J Cell Biol 163(4): 777-787.

48. Small WC, and McAlister-Henn L (1998). Identification of a cytosolically directed NADH dehydrogenase in mitochondria of Saccharomyces cerevisiae. J Bacteriol 180(16): 4051-4055. 9696750.

49. Voisine C, Schilke B, Ohlson M, Beinert H, Marszalek J, and Craig EA (2000). Role of the mitochondrial Hsp70s, Ssc1 and Ssq1, in the maturation of Yfh1. Mol Cell Biol 20(10): 3677-3684. 10779357. PMID: 10779357

50. Ruetenik AL, Ocampo A, Ruan K, Zhu Y, Li C, Zhai RG, and Barrientos A (2016). Attenuation of polyglutamine-induced toxicity by enhancement of mitochondrial OXPHOS in yeast and fly models of aging. Microb Cell 3(8): 338-351.

51. Kerbey AL, Randle PJ, Cooper RH, Whitehouse S, Pask HT, and Denton RM (1976). Regulation of pyruvate dehydrogenase in rat heart. Mechanism of regulation of proportions of dephosphorylated and phosphorylated enzyme by oxidation of fatty acids and ketone bodies and of effects of diabetes: role of coenzyme A, acetylcoenzyme $A$ and reduced and oxidized nicotinamide-adenine dinucleotide. Biochem J 154(2): 327-348.
52. Easlon E, Tsang F, Skinner C, Wang C, and Lin S-J (2008). The malate-aspartate NADH shuttle components are novel metabolic longevity regulators required for calorie restriction-mediated life span extension in yeast. Genes Dev 22(7): 931-944.

53. Kwon Y-Y, Lee S-K, and Lee C-K (2017). Caloric Restriction-Induced Extension of Chronological Lifespan Requires Intact Respiration in Budding Yeast. Mol Cells 40(4): 307-313.

54. Christensen CE, Karlsson M, Winther JR, Jensen PR, and Lerche MH (2014). Non-invasive in-cell determination of free cytosolic $[\mathrm{NAD}+] /[\mathrm{NADH}]$ ratios using hyperpolarized glucose show large variations in metabolic phenotypes. J Biol Chem 289(4): 2344-2352.

55. Warburg O (1956). On respiratory impairment in cancer cells. Science 124(3215): 269-270. 13351639. PMID: 13351639

56. Gietz RD, Schiestl RH, Willems AR, and Woods RA (1995). Studies on the transformation of intact yeast cells by the LiAc/SS-DNA/PEG procedure. Yeast Chichester Engl 11(4): 355-360.

57. Giannattasio S, Liu Z, Thornton J, and Butow RA (2005). Retrograde response to mitochondrial dysfunction is separable from TOR1/2 regulation of retrograde gene expression. J Biol Chem 280(52): 42528-42535.

58. Büttner S, Ruli D, Vögtle F-N, Galluzzi L, Moitzi B, Eisenberg T, Kepp $\mathrm{O}$, Habernig L, Carmona-Gutierrez D, Rockenfeller $\mathrm{P}$, Laun $\mathrm{P}$, Breitenbach $M$, Khoury C, Fröhlich K-U, Rechberger G, Meisinger C, Kroemer $\mathrm{G}$, and Madeo $\mathrm{F}$ (2011). A yeast $\mathrm{BH} 3$-only protein mediates the mitochondrial pathway of apoptosis. EMBO J 30(14): 2779-2792. 